\title{
Relationship between exercise capacity and heart rate variability: Supine and in response to an orthostatic stressor
}

\author{
Catharina C. Grant $^{\text {a, }}$, Jimmy R. Clark ${ }^{\text {b }}$, Dina C. Janse van Rensburg ${ }^{\text {a }}$, Margaretha Viljoen ${ }^{\text {c }}$ \\ a Section Sports Medicine, Faculty of Health Sciences, University of Pretoria, South Africa \\ b Department of Biokinetics, Sport \& Leisure Science, Faculty of Health Sciences, University of Pretoria, South Africa \\ c Department of Physiology, Faculty of Health Sciences, University of Pretoria, South Africa
}

\begin{abstract}
A b s t r a c t
The study investigated whether supine-measured HRV indicators, and/or HRV indicators measured during orthostatic stress are related to conventional measures of exercise and performance ability such as $\mathrm{VO}_{2 \max }$. Only two significant correlations (pb0.05) out of 30 tests were found between supinedetermined HRV indicators and conventional measures. In contrast, fifteen of the 30 relationships calculated during orthostatic stress were significant. Relationships were at best low to moderate $(0.2 \mathrm{~b} \mid$ corr $\mid \mathrm{b} 0.4)$. As expected, the relationships obtained during orthostatic stress were reversed from that obtained in the supine position. In summary, although HRV indicators are related to cardiovascular fitness, correlations between $\mathrm{VO}_{2 \max }$ and these parameters are found only under very specific conditions. HRV parameters explain very little of the variance in $\mathrm{VO}_{2 \max }$. In addition, estimating the exercise capacity from HRV indicators requires experience and extreme caution
\end{abstract}

Maximal oxygen uptake $\left(\mathrm{VO}_{2 \max }\right)$ is widely used as an indicator of exercise capacity and predictor of survival and performance in a variety of clinical and athletic populations (Stelken et al., 1996; Diamond, 2007). $\mathrm{VO}_{2 \max }$ is normally assessed in a laboratory setting by means of respiratory gas analysis equipment. This method is expensive, time consuming and requires the expertise of qualified laboratory personnel. Currently, an increasing number of studies employ the more accessible resting heart rate variability (HRV) indicators as prognostic indicators of survival in patients and of training status in athletes (Gilliam et al., 2007; Achten and Jeukendrup, 2003). HRV represents the changes in instantaneous heart rate over a segment or the full length of an RR interval recording (tachogram), as controlled by the sympathetic and parasympathetic branches of the autonomic nervous system (ANS) (Task Force, 1996). In this respect HRV analysis is used as a non-invasive indicator of ANS function and window on the clinical or training status of patients and athletes.

In testing the assumption that HRV as determined by off-the-shelf HR monitors can be used in place of the more cumbersome and ten times more expensive than $\mathrm{VO}_{2 \max }$ assessment, correlations were found between resting $\mathrm{HRV}$ indicators and $\mathrm{VO}_{2 \max }$. However, results are inconsistent and studies reported significant correlations as well as no correlations between $\mathrm{VO}_{2 \max }$ and the same HRV indicators (Bucheit and Gindre, 2006; Marocolo and Nadal, 2007; Bosquet and Gamelin, 2007; Kouidi et al., 2002; Sendelides et al., 2003). It is suggested that an explanation for the disparity could lie in the differences between the subjects investigated (Kouidi et al., 2002). That is, the $\mathrm{HRV}-\mathrm{VO}_{2 \max }$ relationship may be affected by sport type and training pattern, since a significant relationship $(r=0.61$, pb0.05) has been reported between the $\mathrm{VO}_{2 \max }$ and $\mathrm{HRV}$ in longdistance athletes and soccer players, but not in sprinters, throwers and untrained subjects (Kouidi et al., 2002; Sendelides et al., 2003).

Currently there are HRV software programs available which estimate $\mathrm{VO}_{2 \max }$ without conventional laboratory-based measurements (Smolander et al., 2008). Units for HRV analysis using only two to five minute tachograms with zero post-test analysis time, developed and validated for athletes, are also available (Berkoff et al., 2007). However, the cost of such equipment, ranging in the region of tens of thousand US Dollars, limits its accessibility. Here RR intervals are sampled in a supine position over a short period without the aid of highly trained laboratory personnel. Expensive software is then used to instantly calculate HRV indicators and provide interpretation and recommendations concerning the health and function of the ANS, as well as an estimate of the participant's $\mathrm{VO}_{2 \max }$. The use of supine-determined HRV (regulated mainly by parasympathetic neural influence) to estimate an individual's cardio-pulmonary functional capacity (highest measured rate of whole body oxygen uptake during dynamic exercise), may be extremely valuable in the day-to-day monitoring of patient as well as athlete populations.

Recently, the HRV response to standing (regulated by the withdrawal of the parasympathetic and increase of sympathetic neural influence) was reported to relate to volume of regular exercise 
(Gilder and Ramsbottom, 2008). However, little is known about the association between $\mathrm{HRV}$ in the standing position and $\mathrm{VO}_{2 \max }$. In view of the conflicting reports on the relationship between $\mathrm{VO}_{2 \max }$ and supine $\mathrm{HRV}$, it was decided to investigate the relationship between HRV indicators and selected exercise test parameters as determined in a research laboratory with standardized equipment and methodology. Information on similarities and differences between HRV indicators measured in the supine position (regulated by increased parasympathetic tone) and standing position (regulated by decreased parasym-pathetic and increased tone) may provide novel information to be used by clinicians and coaches when swift evaluation of autonomic control and cardiac health in patient and athlete populations are necessary.

The purpose of this study was thus to determine whether supine HRV indicators, and/or HRV indicators measured during an orthostatic stressor are related to conventional measures of exercise test performance such $\mathrm{VO}_{2 \max }$, peak exercise load and maximum $\mathrm{O}_{2}$ pulse $\left(\mathrm{O}_{2}\right.$ pulse max $)$.

Participants consisted of forty healthy, moderately active males 18-25 years of age (Mass $=74.87 \pm 9.43 \mathrm{~kg}$; BMI $=23.56 \pm 2.68$ ). Moderately active was defined as performing leisure physical activity sessions of not more than a 30 minute duration 2-3 times per week, excluding any purposeful training. None of the participants were professional athletes. Typical activities included cycling, squash, tennis playing, jogging and abseiling. RR intervals were sampled after a 10 minute supine resting period, using the last 5 minute tachograms registered in the supine position and 5 minute tachograms registered during an orthostatic stressor (measured during the first 5 min upon standing upright, leaning with their backs against the wall and feet apart).

The exercise test consisted of a continuous progressive treadmill exercise test to volitional exhaustion. Subjects were permitted 5 min of light stretching prior to a 5 minute run at $10 \mathrm{~km} \mathrm{~h}^{-1}$ to warm up. Thereafter, treadmill speed was increased by $1 \mathrm{~km} \mathrm{~h}^{-1}$ every minute and grade by $0.5 \%$ every 2 min. Pulmonary gas exchange and heart rate (HR) were analyzed continuously during the test using an automated ergo-spirometer and electrocardiograph (Schiller CS-200, Ganshorn Medizi, Niederlauer). $\mathrm{VO}_{2 \max }$ was recorded as the highest oxygen uptake $\left(\mathrm{VO}_{2}\right)$ averaged over $30 \mathrm{~s}$ of the test and reported in relative terms ( $\mathrm{ml} \cdot \mathrm{kg}$ body mass $\left.{ }^{-1} \cdot \mathrm{min}^{-1}\right)$. The $\mathrm{O}_{2}$ pulse max was calculated as the maximal quotient of $\mathrm{VO}_{2}$ and $\mathrm{HR}$ during the test. Peak treadmill speed was recorded as the highest treadmill running speed achieved at the termination of the test.

The RR interval (also called NN interval) data obtained (RS800sd Monitor, Polar, Finland) was transferred to a computer and analyzed with Polar software obtained from the University of Kuopio, Finland. The time domain, frequency domain and the Poincaré plot analysis methods were used in the evaluation of HRV from RR interval data sets (Stein, et al., 1993; Task Force, 1996; Kleiger et al., 2005). Time domain indicators were determined by direct statistical analysis of the time (ms) between consecutive heart beats. Calculated indicators included average SDNN (the standard deviation of normal-to-normal inter-beat intervals, estimating overall HRV), RMSSD (the square root of the mean squared differences of successive RR intervals and an estimate of vagal influence or short term HRV components), PNN50 (percentage of successive RR interval differences larger than 50 ms computed over the entire recording and an indicator of vagal influence or short term HRV). The power spectrums of the RRintervals were obtained with autoregressive spectral analysis. The two main frequency bands observed in this study were: LF (low frequency: between $0.05 \mathrm{~Hz}$ and $0.15 \mathrm{~Hz}$ ) and $\mathrm{HF}$ (high frequency: from $0.15 \mathrm{~Hz}$ to $0.4 \mathrm{~Hz}$ ). LF and HF power was calculated in $\mathrm{ms}^{2}$ and normalized units (percentage of LF+HF), as well as the ratio of the two, i.e. LF/HF. Power spectrum analysis of the tachograms is able to distinguish between the intrinsic sources of HRV, as these rhythms occur at different frequencies. LF power is not only an indicator of sympathetic influence, but also includes a parasympathetic component.
HF power is an indicator of only parasympathetic influence and LF/HF represents the balance between the sympathetic and parasympathetic branches of the ANS (Akselrod et al., 1981). The RR intervals of the tachograms were plotted as a function of the preceding intervals, to produce a Poincaré plot. From this graph, two HRV indicators, SD1 and SD2, were determined. SD1 is an indicator of the standard deviation of the immediate, or short term, RR variability due to parasympathetic efferent (vagal) influence on the sino-atrial node. SD2 is an indicator of the standard deviation of the long-term or slow variability of the heart rate. It is accepted that this value is a representative of the global variation in HRV (Tulppo et al., 1996).

The correlation between these HRV indicators and the measures of exercise test performance was calculated using Spearman's rho, a nonparametric version of the Pearson correlation coefficient based on the ranks of the values, as the data did not satisfy the normality assumption. To separate associations of interest between variables, correlations were defined as follows; no significant correlation: |corr|b 0.2; Low-moderate correlation: $0.2 \mathrm{~b} \mid$ corr|b0.4; Moderate correlation: $0.4 \mathrm{~b}|\mathrm{corr}| \mathrm{b} 0.6$ and statistical significance at pb0.05.

The results of this study are summarised in Table 1, indicating those HRV indicators, as measured in the supine and standing position, for which significant correlations ( $\mathrm{pb} 0.05$ ) were found with the indicators of physical fitness. Only two significant correlations from a possible 30 were found between the supine-determined HRV indicators and $\mathrm{VO}_{2 \max }$. The correlation between $\mathrm{LF}$ nu (normalized unit of power) and $\mathrm{VO}_{2 \max }$ was $\mathrm{r}=-0.32$; $\mathrm{p}=0.042$ and between $\mathrm{LF} / \mathrm{HF}$ and $\mathrm{VO}_{2 \max } \mathrm{r}=-0.32 ; \mathrm{p}=0.043$. According to these negative correlations between $\mathrm{VO}_{2 \max }$ and the two HRV indicators, supine sympathetic nervous system activity is lower in fitter individuals. These results are supported by several published studies (Nagai et al., 2004; Spierer et al., 2007; Gilder and Ramsbottom, 2008). No significant correlations were found between supine $\mathrm{HRV}$ indicators and $\mathrm{O}_{2}$ pulse max or peak treadmill speed.

During the orthostatic stressor (standing) fifteen out of thirty, moderate significant relationships were found between measures of physical fitness and HRV indicators. The correlations obtained (Table 1) during the orthostatic stressor were opposite to those obtained during the supine position, i.e. fitter participants experienced a greater shift towards long-term variation in heart rate as controlled mainly by the sympathetic ANS branch, while in the supine

\section{Table 1}

Correlation between supine and standing HRV indicators and measures of exercise test performance.

\begin{tabular}{|c|c|c|c|c|c|c|}
\hline \multirow{2}{*}{$\begin{array}{l}\text { HRV } \\
\text { indicator }\end{array}$} & \multicolumn{3}{|l|}{ Supine } & \multicolumn{3}{|l|}{ Standing } \\
\hline & $\mathrm{VO}_{2}$ & $\begin{array}{l}\mathrm{O}_{2} \text { pulse } \\
\max \end{array}$ & $\begin{array}{l}\text { Max } \\
\text { speed }\end{array}$ & $\mathrm{O}_{2} \max$ & $\begin{array}{l}\mathrm{O}_{2} \text { pulse } \\
\max \end{array}$ & $\begin{array}{l}\text { Max } \\
\text { speed }\end{array}$ \\
\hline RRSD & $\begin{array}{l}-0.10 \\
(p=0.76\end{array}$ & $\begin{array}{l}0.03 \\
(p=0.40)\end{array}$ & $\begin{array}{l}0.04 \\
(p=0.79)\end{array}$ & $\begin{array}{l}-0.26 \\
(p=0.10)\end{array}$ & $\begin{array}{l}0.00 \\
(p=0.90)\end{array}$ & $\begin{array}{l}-0.15 \\
(p=0.36)\end{array}$ \\
\hline RMSSD & $\begin{array}{l}-0.1 \\
(p=0.60)\end{array}$ & $\begin{array}{l}-0.3 \\
(p=0.03)\end{array}$ & $\begin{array}{l}-0.06 \\
(p=0.73)\end{array}$ & $\begin{array}{l}-0.3^{*} \\
(p=0.04)\end{array}$ & $\begin{array}{l}-0.3 \\
p=0.08\end{array}$ & $\begin{array}{l}18 \\
=0.26)\end{array}$ \\
\hline PNN50 & $\begin{array}{l}0.03 \\
(\mathrm{p}=0.86)\end{array}$ & $\begin{array}{l}-0.3 \\
(p=0.05)\end{array}$ & $\begin{array}{l}0.07 \\
(p=0.67)\end{array}$ & $\begin{array}{l}-0.3^{*} \\
(p=0.04)\end{array}$ & $\begin{array}{l}-0.3^{*} \\
(p=0.07)\end{array}$ & $\begin{array}{l}-0.16 \\
(p=0.22)\end{array}$ \\
\hline SD1 & $\begin{array}{l}-0.08 \\
(p=0.6)\end{array}$ & $\begin{array}{l}-0.34 \\
(p=0.03)\end{array}$ & $\begin{array}{l}-0.05 \\
(p=0.75)\end{array}$ & $\begin{array}{l}-0.3^{*} \\
(\mathrm{p}=0.04)\end{array}$ & $\begin{array}{l}-0.3 \\
(p=0.1)\end{array}$ & $\begin{array}{l}-0.17 \\
(\mathrm{p}=0.28)\end{array}$ \\
\hline SD2 & $\begin{array}{l}-0.15 \\
(p=0.37)\end{array}$ & $\begin{array}{l}-0.19 \\
(p=0.23)\end{array}$ & $\begin{array}{l}-0.06 \\
(p=0.69)\end{array}$ & $\begin{array}{l}-0.2 \\
(p=0.21\end{array}$ & $\begin{array}{l}-0.02 \\
(p=0.88\end{array}$ & $\begin{array}{l}-0.05 \\
(\mathrm{p}=0.78)\end{array}$ \\
\hline $\begin{array}{c}\text { LF Power } \\
\text { nu }\end{array}$ & $\begin{array}{l}-0.32 \\
(p=0.04)\end{array}$ & $\begin{array}{l}0.06 \\
(p=0.72)\end{array}$ & $\begin{array}{l}-0.05 \\
(p=0.78)\end{array}$ & $\begin{array}{l}0.3 \\
(p=0.03)\end{array}$ & $\begin{array}{l}0.4 \\
(p=0.02)\end{array}$ & $\begin{array}{l}0.4 \\
(\mathrm{p}=0.01)\end{array}$ \\
\hline $\begin{array}{l}\text { LF Power } \\
\mathrm{ms}^{2}\end{array}$ & $\begin{array}{l}-0.3 \\
(p=0.06)\end{array}$ & $\begin{array}{l}-0.16 \\
(p=0.31)\end{array}$ & $\begin{array}{l}-0.14 \\
(p=0.37)\end{array}$ & $\begin{array}{l}-0.2 \\
(p=0.18\end{array}$ & $\begin{array}{l}-0.12 \\
(p=0.47\end{array}$ & $\begin{array}{l}-0.03 \\
(p=0.86)\end{array}$ \\
\hline $\begin{array}{c}\text { HF Power } \\
\text { nu }\end{array}$ & $\begin{array}{l}0.3 \\
(p=0.05)\end{array}$ & $\begin{array}{l}-0.11 \\
(p=0.47)\end{array}$ & $\begin{array}{l}0.04 \\
(p=0.81)\end{array}$ & $\begin{array}{l}-0.3 \\
(p=0.05)\end{array}$ & $\begin{array}{l}-0.4^{*} \\
(\mathrm{p}=0.02)\end{array}$ & $\begin{array}{l}-0.4^{*} \\
(\mathrm{p}=0.01)\end{array}$ \\
\hline $\begin{array}{l}\text { HF Power } \\
\mathrm{ms}^{2}\end{array}$ & $\begin{array}{l}0.06 \\
(p=0.72)\end{array}$ & $\begin{array}{l}-0.03 \\
(p=0.44)\end{array}$ & $\begin{array}{l}-0.03 \\
(p=0.86\end{array}$ & $\begin{array}{l}-0.3^{*} \\
(\mathrm{p}=0.04)\end{array}$ & $\begin{array}{l}-0.4^{*} \\
(\mathrm{p}=0.02)\end{array}$ & $\begin{array}{l}-0.3^{*} \\
(\mathrm{p}=0.04)\end{array}$ \\
\hline $\mathrm{LF} / \mathrm{HF}$ & $\begin{array}{l}-0.32 \\
(p=0.04)\end{array}$ & $\begin{array}{l}0.09 \\
(p=0.59)\end{array}$ & $\begin{array}{l}-0.05 \\
(p=0.76)\end{array}$ & $\begin{array}{l}0.3 \\
(\mathrm{p}=0.04)\end{array}$ & $\begin{array}{l}0.4 \\
(\mathrm{p}=0.02)\end{array}$ & $\begin{array}{l}0.4 \\
(\mathrm{p}=0.01)\end{array}$ \\
\hline
\end{tabular}

Statistical significance at pb0.05. Associations not significant: |corr|b0.2; Lowmoderate: $0.2 \mathrm{~b} \mid$ corr|b0.4; Moderate: $0.4 \mathrm{~b} \mid$ corr|b0.6. 
position the fitter participants showed the higher short term, vagal induced variation. In view of the above it is obvious that $\mathrm{HRV}$ indicator values cannot summarily be used as indicators of cardiovascular fitness or capacity, and that the reciprocal action of sympathetic and parasympathetic branches of the ANS during body position changes should be taken into account.

These HRV results are in line with what is known from studies in athletes indicating that regular exercise (higher $\mathrm{VO}_{2 \max }$ ) benefits the resting ANS by increasing HRV, lowering the sympathetic influence on the heart and increasing the parasympathetic influence (Nagai et al., 2004; Spierer et al., 2007; Gilder and Ramsbottom, 2008). It also confirms that only a limited number of HRV indicators, based on weak associations in the supine position, could perhaps be used to estimate vo2max.

However, this study also clearly demonstrates the novel relationship between HRV indicators and indicators of physical fitness during an orthostatic stressor. Participants with greater physical fitness showed increased responsiveness (indicated by increased sympathetic activity and vagal withdrawal) to the orthostatic challenge. These results can be explained by the fact that the maintenance of blood pressure in standing up from the supine position is dependent on increased sympathetic activity and vagal withdrawal, while the supine position is marked by vagal activation with sympathetic withdrawal (Pagani et al., 1986).

This is an important fact to remember in any attempt to estimate fitness and capacity from HRV values and when using 24 hour recordings of RR interval which includes supine and mobile phases. Also of interest is the observation that many more HRV indicators showed significant correlations with cardiopulmonary fitness indicators $\left(\mathrm{VO}_{2 \max }\right.$, peak treadmill speed and $\mathrm{O}_{2}$ pulse max) during the orthostatic challenge compared to the supine measures. The possibility that these results may relate to exercise induced changes in baro-receptor sensitivity, responsiveness of the cardio vascular control centre and sympathetic branch sensitivity, warrants further investigation.

In summary it can be said that $\mathrm{HRV}$ indicators are related to conventional measures of cardiopulmonary fitness and capacity such as $\mathrm{VO}_{2 \max }$, peak treadmill speed and $\mathrm{O}_{2}$ pulse max. However, estimating exercise capacity from HRV indicators requires experience and should be done with extreme caution, since relationships were only weak to moderate at best $(0.2 \mathrm{~b} \mid$ corr $\mid \mathrm{b} 0.4)$ and indicators may show positive or negative correlations with exercise measures When such procedures are made use of in patient and athlete studies, HRV indicators measured during an orthostatic challenge may represent a more sensitive method of estimating exercise capacity compared to supine measures. However, the differences in ANS response between these modes should be noted. Further, it is clear that HRV measures, both supine and standing, explain very little of the variance in $\mathrm{VO}_{2 \max }$. More research is needed to better understand ANS responses to orthostatic stressors and how these are related to HRV indicators, particularly against the background of varying exercise capacity.

\section{References}

Achten, J., Jeukendrup, A.E., 2003. Heart rate monitoring: applications and limitations.Sports Med. 33, 517-538.

Akselrod, S., Gordon, D., Ubel, A., Shannon, D.C., Barger, A.C., Cohen, R.J., 1981. Power spectrum analysis of heart rate fluctuation: a quantitative probe of beat-to-beat cardiovascular control. Science 213, 220-222.

Berkoff, D.J., Cairns, C.B., Sanchez, L.D., Moorman, C.T., 2007. Heart rate

variability in elite American track-and-field athletes. J. Strength Cond. Res. 21, 227-231.

Bosquet, L., Gamelin, F., 2007. Is aerobic endurance a determinant of cardiac autonomic regulation? Eur. J. Appl. Physiol. 100, 363-369.

Bucheit, M., Gindre, C., 2006. Cardiac parasympathetic regulation: respective associations with cardiorespiratory fitness and training load. Am. J. Physiol. Heart Circ. Physiol. 291, 451-458.

Diamond, E., 2007. Developing a cardiopulmonary exercise testing laboratory. Chest 132, 2000-2007.

Gilder, M., Ramsbottom, R., 2008. Change in heart rate variability following orthostasis relates to volume of exercise in healthy woman. Aut. Neurosci. 143, 73-76.

Gilliam, F.R., Kaplan, A.J., Black, J., Chase, K.J., Mullin, C.M., 2007. Changes in heart rate variability, quality of life, and activity in cardiac resynchronization therapy patients. PACE 30, 56-64.

Kleiger, R.E., Stein, P.K., Bigger Jr., T., 2005. Heart rate variability: measurement and clinical utility. Ann. Noninvasive Electrocardiol. 10, 88-101.

Kouidi, E., Haritondis, K., Kotlianos, N., Deligiannis, A., 2002. Effects of athletic training on heart rate variability triangular index. Clin. Physiol. Funct. Imaging 22, 279-284. Marocolo, M., Nadal, J., 2007. The effect of an aerobic training program on the electrical remodelling of heart high-frequency components of the signal-averaged electrocardiogram is a predictor of the maximal aerobic power. Braz. J. Med. Biol. Res. 40, 199208.

Nagai, N., Hamada, T., Kimura, T., Moritani, T., 2004. Moderate physical exercise increases cardiac autonomic nervous system activity in children with low heart rate variability. Childs Nerv. Sys. 20 (4), 215-200.

Pagani, M., Lombardi, F., Guzzeti, S., Rimoldi, O., Furlan, R., Pizzinelli, P., Sandrone, G. Malfatto, G., Dell'Orto, S., Piccaluga, E., 1986. Power spectral analysis of heart rate and arterial pressure variabilities as a marker of sympatho-vagal interaction in man and conscious dog. Circ. Res. 59, 178-193.

Sendelides, T., Metaxas, T., Koutlianos, N., Kouidi, E., Deligiannis, A., 2003. Heart rate variability changes in soccer players. OÉsterr. J. Sportmed. 33, 10-13.

Smolander, J., Juuti, T., Kinnunen, M.L., Laine, K., Louhevaara, V., Mannikko, K., Rusko, H., 2008. A new heart rate variability-based method for the estimation of oxygen consumption without individual laboratory calibration: application example on postal workers. Applied Ergon. 39, 325-331.

Spierer, D.K., De Meersman, R.E., Kleinveld, J., McPherson, E., Fullilove, R.E., Alba, A., Zion, A.S., 2007. Exercise training improves cardiovascular and autonomic profiles in HIV. Clin. J. Auton. Res. 17, 341-348.

Stein, P.K., Bosner, M.W., Kleiger, R.E., Conger, B.M., 1993. Heart rate variability: a measure of cardiac autonomic tone. Am. Heart J. 127, 1376-1381.

Stelken, A.M., Younis, L.T., Jennison, S.H., Miller, D.D., Miller, L.W., Leslee, J.S., Karql, D., Chaitman, B.R., 1996. Prognostic value of cardiopulmonary exercise testing using percent achieved of predicted peak oxygen uptake for patients with ischemic and dilated cardiomyopathy. J. Am. Coll. Cardiol. 27, 345-352.

Task Force of the European Society of Cardiology and the North American Society of Pacing and Electrophysiology, 1996. Heart rate variability: standards of measurement, physiological interpretation and clinical use. Eur. Heart J. 17, 354-381.

Tulppo, M.P., Makikallio, T.H., Takala, E.S., Seppanen, T., Huikuri, H.V., 1996. Quantitative beat-to-beat analysis of heart rate dynamics during exercise. Am. . Physiol. Heart Circ Physiol. 271, 244-252. 